\title{
LOGÍSTICA REVERSA DE MEDICAMENTOS, INSUMOS E CORRELATOS, APLICAÇÃO, E IMPACTOS NO SETOR PÚBLICO
}

\section{ARTIGO ORIGINAL}

ALENCAR FILHO, João Reginaldo de ${ }^{1}$

\begin{abstract}
ALENCAR FILHO, João Reginaldo de. Logística Reversa de Medicamentos, Insumos e Correlatos, aplicação, e impactos no Setor Público. Revista Científica Multidisciplinar Núcleo do Conhecimento. Ano 05, Ed. 11, Vol. 15, pp. 33-43. Novembro de 2020. ISSN: 2448-0959, Link de acesso: https://www.nucleodoconhecimento.com.br/saude/insumos-e-correlatos
\end{abstract}

\section{RESUMO}

O presente estudo visa discorrer sobre os resultados da gestão de logística de suplementos e produtos acabados, voltados para a área de medicamentos e correlatos em transportes, locais de armazenamentos, e distribuição no setor público e seu subsequente impacto na saúde pública. Para a realização do presente estudo, foram utilizadas informações produzidas em reportagens no período de 2010 a 2017, além de consultas à dados divulgados em periódicos, livros, artigos, e revistas eletrônicas. Este artigo também pretende apresentar as dificuldades em face da aparente falta de uma melhor administração pública e de gerenciamento da cadeia produtiva de logística de medicamentos, descrevendo as atividades e seus desafios mediante os resultados. É notório que há um grande déficit na logística farmacêutica e de gestão de serviços empreendida pelo setor público, de forma a tornar premente a elaboração de um projeto que venha satisfazer as necessidades do setor, no tocante ao melhoramento dos serviços, por meio da ação de colaboradores qualificados, que possam atuar nos processos administrativos, como gerenciamento e solicitações de compras, de forma a oferecer transparência e eficiência. Isso poderá ser satisfeito com a implantação de uma gestão e de um gerenciamento logístico mais atuante e

\footnotetext{
${ }^{1}$ Graduado em Farmácia.
} 
responsável na implementação dos processos operacionais até a entrega dos produtos ao consumidor final.

Palavras-chave: Logística de medicamentos, logística reversa, Setor público, Saúde pública, Meio ambiente.

\section{INTRODUÇÃO}

Esta pesquisa tem como objetivo expor, através de dados e de documentos, que demonstrem como os recursos públicos são usados e qual a importância do processo administrativo e operacional da logística reversa do setor farmacêutico no atendimento ao setor público consumidor, objetivando garantir a saúde pública, evitar danos â saúde ao meio ambiente.

O emprego da logística reversa de medicamentos e correlatos tem por finalidade receber os produtos descartados, seja pelo consumidor final, seja por entidades públicas ou privadas, de forma a garantir a preservação do meio ambiente e da saúde pública. Assim, controla o descarte e o destino correto do lixo, que seriam de responsabilidade dos laboratórios que os produzem.

A qualidade nas operações de recebimento, armazenamento, distribuição, movimentação e aquisição desses produtos específicos geram a movimentação de bilhões de reais e tem suas operações comerciais de produtos, como medicamentos, insumos e correlatos do segmento da saúde, que tenta acompanhar o crescimento da população e a da tecnologia. Nos dias atuais o consumo se mostra cada vez mais agressivo, em virtude da acessibilidade tanto de informações como de acesso às diversas campanhas publicitárias para gerar vendas. Todo esse fluxo acaba gerando um grande descarte de restos e lixos provenientes desse consumo (ANVISA, 2010).

O risco ao meio ambiente, em virtude do grande consumo da população, quer por falta de educação e/ou de desconhecimento de como descartar os resíduos, acaba por poluir ruas e a própria natureza, o que acaba por causar diversas doenças. Isso acaba gerando grandes despesas para a administração pública, que como consequência, 
precisará tratar a população com serviços públicos de saúde, além dos custos com medicamentos.

Ao fim de todo esse processo, a falta de profissionais especializados em administração e logística para controlar a compra, distribuição e conservação desses medicamentos também geram grandes problemas, geralmente de gestão, como por exemplo, a falta e controle do vencimento de medicamentos e insumos (AGÊNCIA BRASIL, 2011).

\section{DESENVOLVIMENTO}

Segundo o Ministério do Meio Ambiente, a logística reversa "é um dos instrumentos para aplicação da responsabilidade compartilhada pelo ciclo de vida dos produtos" (MMA, 2020.). Com esse objetivo, em 2010, foi editada a Lei oㅜ 12.305, de 2 de agosto, regulamentada pelo Decreto $\mathrm{n}^{-} \mathbf{7 . 4 0 4}$, de 23.12.2010, complementado os arts. $16 \mathrm{e}$ 17, pelo Decreto no 9.177, de 23 de 10 de 2017, cujas ações foram emanadas da Política Nacional de Resíduos Sólidos (PNRS, 2010) no país.

Ainda, segundo o Ministério do Meio Ambiente, a PNRS definiu a logística reversa como um

instrumento de desenvolvimento econômico e social caracterizado por um conjunto de ações, procedimentos e meios destinados a viabilizar a coleta e a restituição dos resíduos sólidos ao setor empresarial, para reaproveitamento, em seu ciclo ou em outros ciclos produtivos, ou outra destinação final ambientalmente adequada. (MMA, 2020).

Em linguagem simples, equivale dizer que a logística reversa se torna um instrumento para o controle do lixo gerado pelas diversas instituições públicas ou privadas quando a produção e comercialização de produtos acabam virando lixo, após o uso pelos possíveis consumidores.

No segmento de medicamentos como outros tantos, um conjunto de operações complexas e relevantes para a organização do transporte de carga e descarga, como, armazenamento e distribuições para as bases de apoio à saúde e manutenção de 
inúmeros depósitos para alocação dos produtos e insumos, devem seguir um rigoroso sistema de qualidade nas operações, além da importância de que todos os gestores, e quem está envolvido no processo operacional, tenham treinamento e qualificação, a fim de garantir a satisfação das exigências no âmbito da rede pública de saúde brasileira.

$\mathrm{Na}$ logística administrativa e operacional nos serviços da saúde pública, para a atividade de aquisição, o setor precisa conhecer a demanda exata para atender as necessidades da localidade, garantindo assim, que seu estoque esteja sempre em dia e com prazo de validade positivo. Isso é fundamental para que o gestor trabalhe, não só com uma margem de segurança, como também vai proporcionar uma interação equilibrada entre os setores, em relação às trocas e transferências.

A movimentação, dentro e fora do armazém ou fábrica deve-se garantir a segurança e a qualidade dos produtos e serviços prestados, a serem desempenhados com equipamentos e EPIS.

$\mathrm{O}$ armazenamento dos produtos $\mathrm{e}$ insumos deve assegurar que produtos $\mathrm{e}$ instalações logísticas estejam de acordo com a garantia e conservação dos produtos.

$\mathrm{Na}$ distribuição; todo processo de expedição deve atender às regras de transporte, com caminhões que atendam às exigências para garantir a qualidade do produto. Toda a etapa de distribuição deve ser prestada por pessoal qualificado e capacitado, a fim de garantir uma movimentação satisfatória na operacionalização do serviço.

A logística nacional nos serviços de saúde pública enfrenta uma grande falta de profissionais qualificados e treinados para atender as necessidades das várias localidades no Brasil, seja em nível estadual, municipal ou distrital, que necessitam do serviço de logística de medicamentos e de logística reversa de medicamentos.

O Sistema Único de Saúde (SUS, 1988) foi regulamentado com o implemento da Constituição Federal em 05 de outubro de 1988, para assegurar que a saúde é direito de todos e dever do Estado, cujos princípios estão alicerçados em ações do governo submetidas ao controle social e cujo custeio se dá com recursos da seguridade social 
(33\%), nas três esferas do governo, tendo a participação do setor privado em caráter complementar e sob as regras pública. (CEBES, 2010).

Somado mais uma década depois, conclui-se que o setor de saúde pública ainda convive envolto em infindáveis crises, que minam os recursos públicos, a saúde pública e o meio ambiente.

Um dos fatores que contribui com tal realidade e que se pretende destacar aqui sobre os profissionais do setor, que apresentam pouca ou nenhuma qualificação para atuar nas responsabilidades operacionais que demandam a área de saúde relacionada a medicamentos e produtos médicos. Esse despreparo em mão de obra qualificada, pode acabar culminando em erros e riscos para a saúde das pessoas que precisam utilizá-los e que não estão conscientizadas de como descartar o lixo advindo desses produtos, afetando assim, negativamente, o meio ambiente.

Um profissional qualificado no processo de aquisição de produtos e insumos, além de qualificado, necessitaria ter alguma experiência, para poder avaliar o estado da demanda para realizar uma compra consciente, e operacionalizar os serviços relacionados com o espaço para armazenamento e procedimento de movimentação dos produtos e insumos.

O planejamento que os gestores de centros de distribuições e de hospitais com grande circulação de pessoas e de produtos, nem sempre estão amparados por processos e sistemas modernos que permitiriam agilidade no atendimento e controle da qualidade. Isso dificulta o processamento e controle dos produtos, por falta de planejamento. $O$ Ciclo Evolutivo da Logística atual começa no planejamento, desde estudos sobre demanda, e a necessidade e quantidade de determinados produtos ou insumos. 
Figura 1. Ciclo Evolutivo da Logística

\section{Ciclo Evolutivo da Logística}

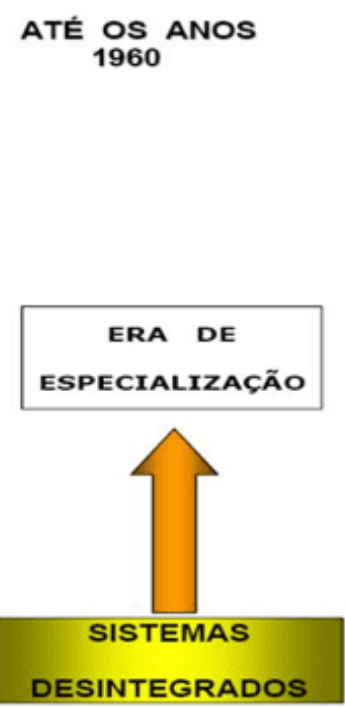
$\underset{1970}{\text { DÉCADA DE }}$

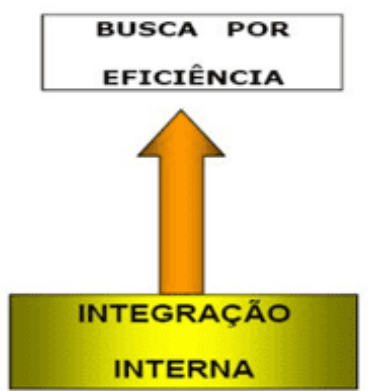

DÉCADA DE 1980

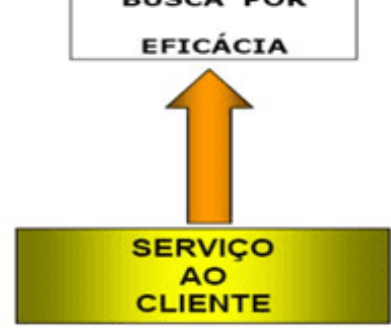

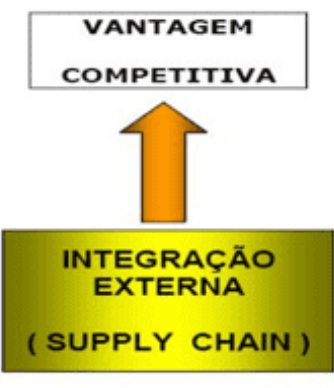

Fonte: Marcilio Cunha 26

Fonte: Marcilo Cunha, 26

Nas empresas ou instituições de saúde, é de máxima importância que as pessoas envolvidas nas atividades de abastecimento de produtos e insumos médicos, tenham a capacidade para desempenhar o serviço de modo a não causar danos provenientes do recebimento, do manejo e do gerenciamento desses materiais.

No caso de instituições hospitalares a logística estuda a sazonalidade de produtos, para de modo estratégico, buscar os melhores fornecedores e melhores preços, com a finalidade de impedir desperdício. Com isso consegue garantir eficiência no processo operacional e qualidade nessa atividade.

Com objetivo maior de evitar erros e danos à saúde das pessoas e ao meio ambiente, a logística reversa está respaldada na Lei 12.305, de 02/08/2010, regulamentada pelos Decretos 7.404 de 23/12/2010 e 9.177 de 23/10/2017, que prevê, entre outras coisas, a implantação do sistema de logística reversa. (MMA, 2020).

Além da regulamentação, a lei estipula outros dois instrumentos para viabilizar a logística reversa: o termo de compromisso e o acordo setorial. 
Figura 2. Decreto institui o sistema de logística reversa de medicamentos

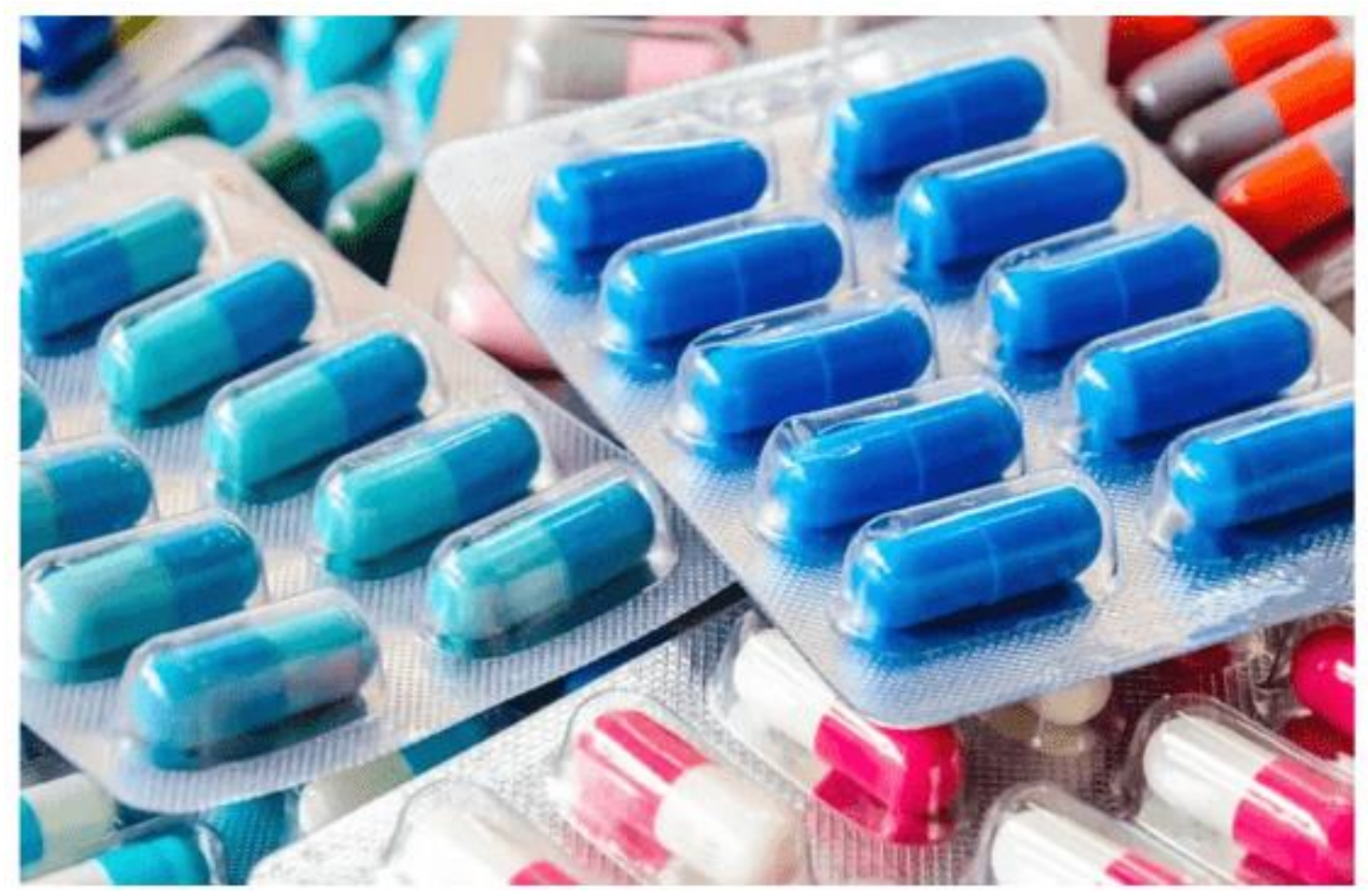

Fonte: GUIA DA FARMACIA, online

De acordo com a Constituição Federal de 1988, a obrigatoriedade de licitar busca a demonstração de eficiência, transparência e moralidade nos negócios administrativos evitando que membros da administração, no seu círculo de amizades pessoais ou familiares, se beneficiem de alguma forma, mesmo que seja em favor do Poder Público. (De acordo com o art. 3ํㅡㅁ Lei 8666/93). 
Figura 3. Logística Reversa

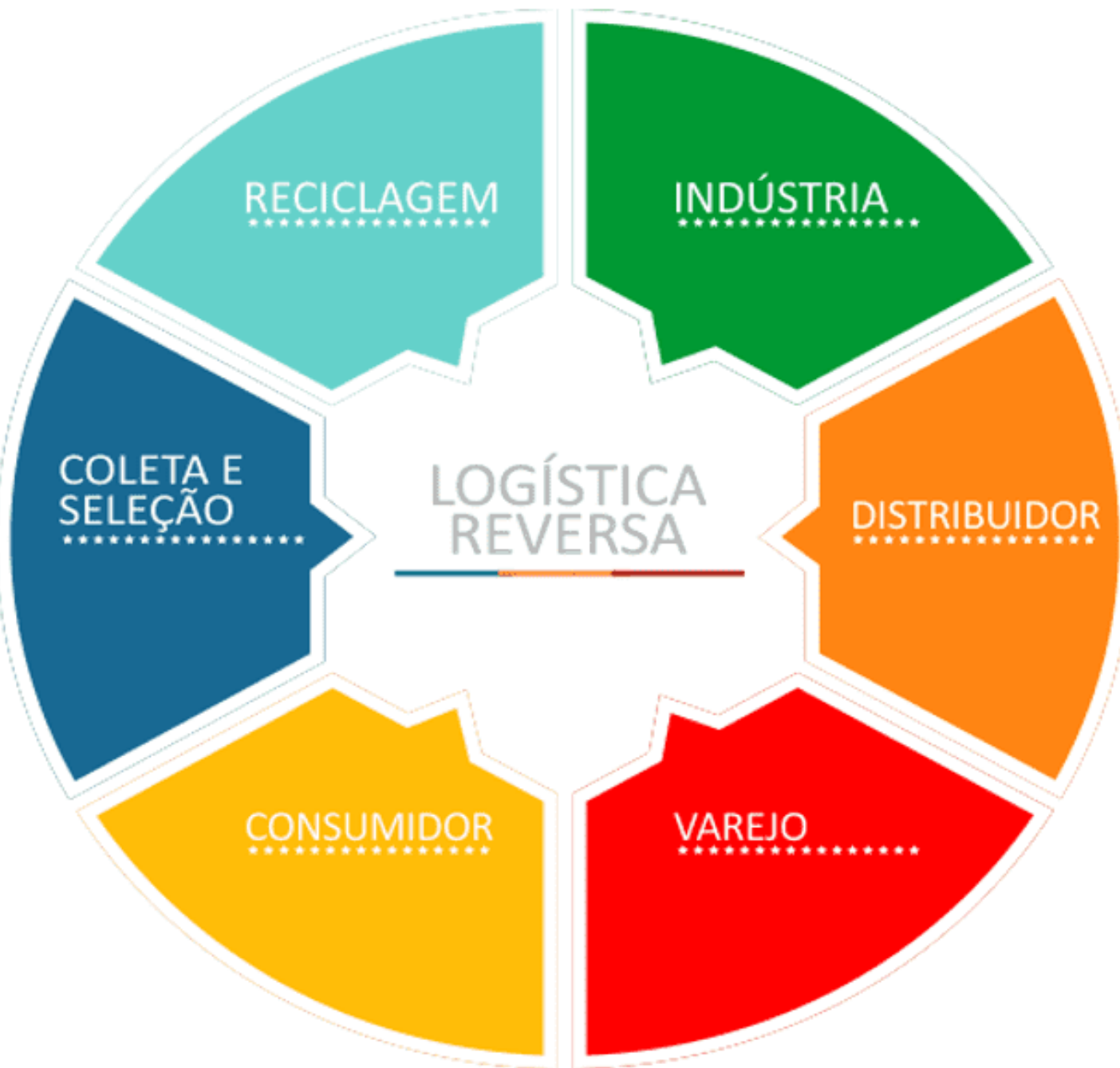

O Decreto ํㅜ 9.177, de 23/10/2017 em seu artigo 1ํ estabelece normas para assegurar a isonomia na fiscalização e no cumprimento das obrigações imputadas aos fabricantes, aos importadores, aos distribuidores e aos comerciantes de produtos, seus resíduos e suas embalagens sujeitos à logística reversa obrigatória.

Dessa forma, as obrigações e responsabilidades, desde a produção e comercialização de produtos e demais resíduos sólidos gerados se torna obrigação compartilhada pelos diversos usuários desses produtos e resíduos gerados, sejam fabricantes, importadores, distribuidores, comerciantes e ou consumidores, garantindo assim, o 
reaproveitamento, a coleta e destinação consciente desses materiais, dando o fim adequado, seja descarte ou reaproveitamento do lixo gerado.

Vale destacar, que no caso de produtos farmacêuticos ou médicos, o Plano de Gerenciamento de Resíduos de Serviços de Saúde - (PGRSS), impõe que o descarte inadequado de medicamentos pode acarretar sanções administrativas, conforme a Lei Federal oㅜ 12.305, de 02/08/2010.

Figura 4. MP apura descarte irregular

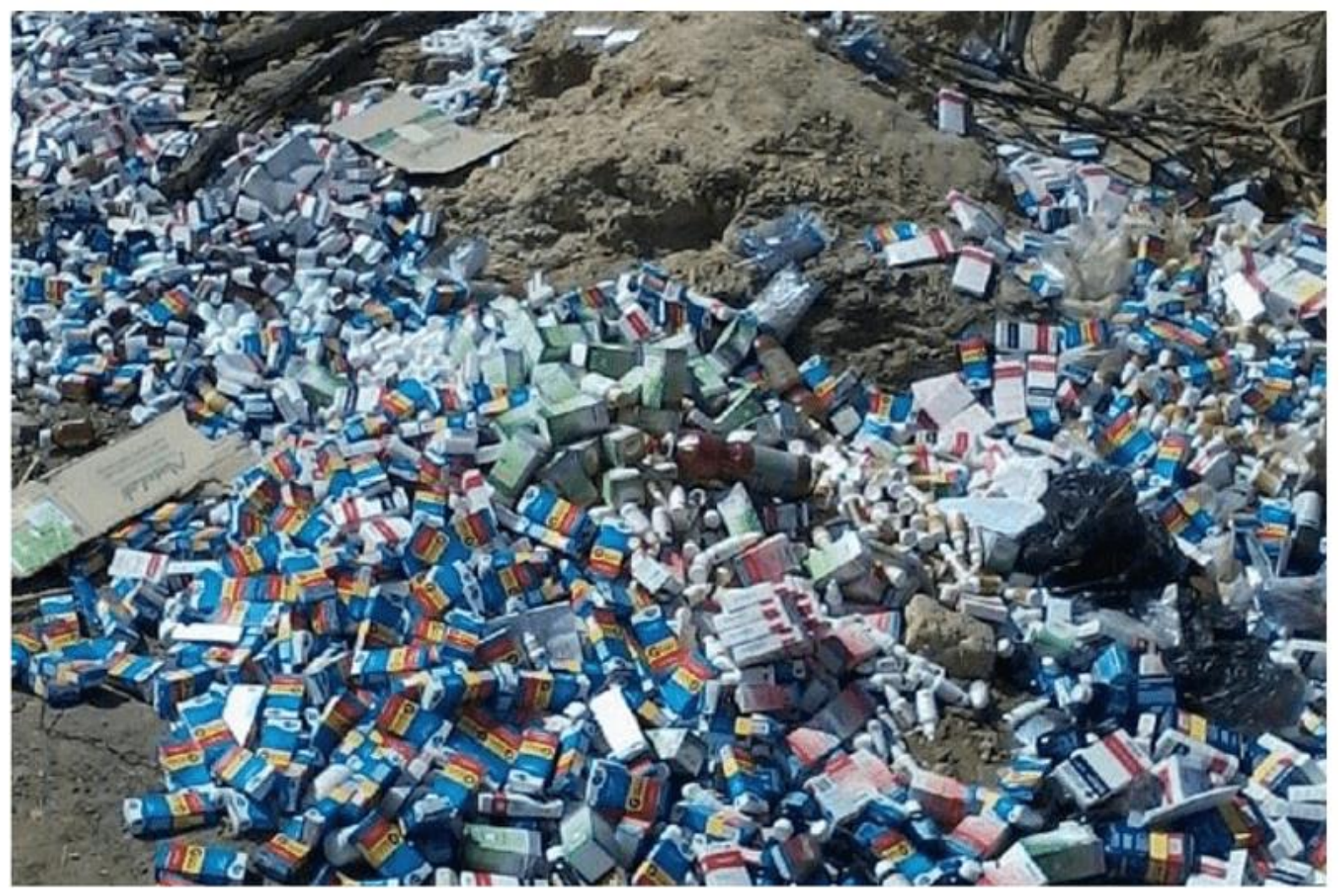

Fonte: tribunadonorte.com.br

\section{CONSIDERAÇÕES FINAIS}

Dado o presente trabalho, e considerando a grande importância no que diz respeito aos resultados da gestão de logística de suplementos e produtos acabados, voltados para a área de medicamentos e correlatos para atendimento ao setor público, concluise que o investimento no fator humano, bem como na conscientização das pessoas 
usuárias desses produtos, pelo setor público, poderá proporcionar uma visão mais moderna e ampla no gerenciamento logístico desses produtos e resíduos gerados, considerando que o envolvimento de todos os responsáveis no processo logístico de materiais e de medicamentos e seus correlatos, poderá culminar em resultados pontuais, visando com isso, empreender maior agilidade nos processos de envolvidos com o retorno e destinação adequada desses produtos ou insumos gerados pela cadeia de medicamentos. Isso acaba por evitar o desperdício dos recursos públicos e mau desempenho do setor demandante, garantindo assim, o desempenho eficaz do ciclo da logística reversa de medicamentos, que certamente gerará o controle do lixo gerado diariamente pelo consumo cada vez maior desses produtos pelo público demandante. Por sua vez, estará garantido também a conservação da natureza, tão necessária e indispensável para a vida neste planeta.

\section{REFERÊNCIAS}

A CONFUSÃO DA LOGÍSTICA REVERSA DE MEDICAMENTO NO BRASIL; Viviane Massi, ICTQ, 2020; Disponível em: https://www.ictq.com.br/varejo-farmaceutico/844a-confusao-da-logistica-reversa-de-medicamentos-no-brasil

AGÊNCIA BRASIL, 2011. Empresa Brasil de Telecomunicação. Relatório de ONU Aponta Consumo Abusivo de Remédios no Brasil. Disponível em:< http://agenciabrasil.ebc.com.br/noticia/2011-06-23/relatorio-da-onu-aponta-consumoabusivode-remedios-no-brasil>. Acesso em 04 abril 2012.

ANVISA, 2010. Agência Nacional de Vigilância Sanitária. Diagnóstico situacional da promoção de medicamentos em unidades de saúde do SUS.

\section{BARBOSA, M. O e-comerce é um parceiro estratégico para o setor da saúde.} Revista Diagnostico, São Paulo, V. 4, n. 17, p. 48, Set. /Out. 2012. Disponível em: < http://www.diagnosticoweb.com.br/noticias/gestao/direto-ao-ponto-o-e-commerce-eparceiro-estrategico-para-asaude.html> Acesso em: 01/06/2017. 
BRASIL. Ministério da Saúde. Apoio à Gestão Hospitalar: E-SUS Hospitalar. Disponível em: http://portalsaude.saude.gov.br/index.php/oministerio/principal/secretarias/sgep/sgep noticias/23553-apoio-a-gestao-hospitalar-e-sus-hospitalar.Acessado em: 10/10/2017

BRASIL. Ministério do Meio Ambiente. Conselho Nacional do Meio Ambiente (CONAMA). Resolução no 358, de 29 de abril de 2005. Dispõe sobre o tratamento e a disposição final dos resíduos dos serviços de saúde e dá outras providências.

BRASIL. Portaria MS n. 3.916, de 30 de outubro de 1998. Política Nacional de Medicamentos. Brasília: Ministério da Saúde, 1998.

BRASIL. Resolução ANVISA RDC n. 306, de 7 de dezembro de 2004. Dispõe sobre o Regulamento Técnico para o gerenciamento de resíduos de serviços de saúde. Brasília: Ministério da Saúde, 2004.

BRASIL. Resolução CONAMA n. 358, de 29 de abril de 2005. Dispõe sobre o tratamento e a disposição final dos resíduos de serviços de saúde e dá outras providências. Brasília: Ministério do Meio Ambiente, 2005.

BUENO, CS., WEBER, D., OLIVEIRA, KR. Farmácia caseira e descarte de medicamentos no bairro Luiz Fogliatto do município ljuí-RS. Rev. Ciências Farm. Básica Apl. 2009; 30(2):75-82.

DEMAJOROVIC, J.; et. al. Logística reversa: como as empresas comunicam o descarte de baterias e celulares? Revista de Administração de Empresas, v. 52, n. 2, p.165-178, 2012.

EICKHOFF, P.; HEINECK, I.; SEIXAS, L. J. Gerenciamento e destinação final de medicamentos: uma discussão sobre o problema. Revista Brasileira de Farmácia, 90 (1), 64-68, 2009. 
FALQUETO, E; KLIGERMAN, D. C; ASSUMPÇÃO, R. F. Como realizar o correto descarte de resíduos de medicamentos? Ciência \& Saúde Coletiva, v.15, n.2, p. 3283-3293, 2010.

FALQUETO, E; KLIGERMAN, D. C. Diretrizes para um Programa de Recolhimento de Medicamentos vencidos no Brasil. Ciência \& Saúde Coletiva, v. 18, n. 3, p. 883892, 2013.

GOUVEIA, N. Resíduos sólidos urbanos: impactos socioambientais e perspective de manejo sustentável com inclusão social. Rev. Ciência \& Saúde Coletiva, 17 (6), 1503-1510, 2012.

MINISTÉRIO DA SAÚDE. Apoio à Gestão Hospitalar: E-SUS Hospitalar.

Disponível em: http://portalsaude.saude.gov.br/index.php/oministerio/principal/secretarias/sgep/sgep noticias/23553-apoio-a-gestao-hospitalar-e-sus-hospitalar.

Enviado: Março, 2020.

Aprovado: Novembro, 2020. 